\title{
Application of fixed regression test-day model for genetic evaluation of Iranian Holsteins
}

\section{Y Shamshirgaran $^{1}$, H Farhangfar ${ }^{2}$, AA Aslaminejad ${ }^{1}$, M Tahmorespour ${ }^{1}$, P Rowlinson ${ }^{3}$}

${ }^{1}$ Ferdowsi University of Mashhad, Mashhad, Islamic Republic of Iran

${ }^{2}$ Birjand University, Birjand, Islamic Republic of Iran

${ }^{3}$ University of Newcastle upon Tyne, Newcastle upon Tyne, United Kingdom

Email: hfarhangfar2003@yahoo.co.uk

Introduction Test-day (TD) models recently have received considerable attention for the genetic evaluation of dairy cattle. In fixed regression test-day models (FRM), TD records within lactation are taken as repeated measurements (Swalve, 2000). This model assumes constant additive genetic and permanent environmental variances throughout the lactation. Furthermore, it is assumed that the genetic and permanent environmental correlations among different TD records are 1. The objective of this study was to apply FRM to monthly test day milk yield trait in first lactation of Iranian Holsteins cattle.

Material and methods A total of 164,391 monthly test day milk records from 19,217 first lactations of Holstein cows calved between 1991 and 2008 and distributed in 172 herds in the Razavi-Khorasan region of Iran were analyzed. A singletrait animal model for fixed regression was applied to TD records of first lactation cows. In this model, fixed effect of contemporary groups of herd-year-month of production (HYM), linear and quadratic covariates of age of calving $\left(\mathrm{A}_{\mathrm{ijkt}}\right)$ and Holstein gene percentage $\left(\mathrm{HF}_{\mathrm{ijkt}}\right)$, third order Legendre polynomials for days in milk, random effects of additive genetic $\left(\mathrm{a}_{\mathrm{j}}\right)$, permanent environment $\left(\mathrm{pe}_{\mathrm{j}}\right)$ and residual $\left(\mathrm{ME}_{\mathrm{ij}}\right)$ were fitted. All genetic relationship among animals was also taken into account. The model equation was

$y_{i j k}=\mu+H Y M_{i}+\sum_{m=1}^{2} \beta_{m} *\left(A_{i j k t}-\bar{A}\right)^{m}+\sum_{m=1}^{2} \delta_{m} *\left(H F_{i j k t}-\overline{H F}\right)^{m}+\sum_{R=0}^{k-1}\left(\gamma_{R} * \phi_{R}(t)\right)+a_{j}+p e_{j}+M E_{i j k}$

The covariance components and genetic parameters were estimated by REML method using DXMRR option of the DFREML software package.

Results Variance components, heritability and repeatability are in table 1.These results are contrary to result of most studies.

Table 5 Estimates of variance components ${ }^{1}$, heritability $\left(\mathrm{h}^{2}\right)$, and repeatability (r) for monthly test-day milk yield

\begin{tabular}{|c|c|c|c|c|c|c|}
\hline Trait & $\overline{\sigma_{a}^{2}}$ & $\sigma_{p e}^{2}$ & $\sigma_{e}^{2}$ & $\sigma_{p}^{2}$ & Heritability & Repeatability \\
\hline $\begin{array}{l}\text { Milk yield } \\
(\mathrm{Kg})\end{array}$ & 4.686 & 11.97 & 13.92 & 30.57 & 0.153 & 0.544 \\
\hline
\end{tabular}

${ }^{1} \sigma_{a}^{2}=$ additive variance, $\sigma_{p e}^{2}=$ permanent environmental variance, $\sigma_{e}^{2}=$ residual variance, $\sigma_{p}^{2}=$ phenotypic variance

Conclusion In general, heritability estimate for monthly milk yield trait of first parity of Iranian Holsteins obtained in this study was low compared with estimates reported by other countries (Mostert et al., 2004). Lower heritability observed here is due to the structure of the data set, lower pedigree information, method of estimation variance covariance components, and the model used for analysis of the data. However the low heritability estimates is attributed to a rather high environmental variance as a result of different system of keeping of dairy cows in Iranian herds that influencing performance of dairy cattle in Iran. Estimate of repeatability is within the range of other studies.

Acknowledgments The authors gratefully acknowledge the Ministry of Agricultural Jihad of Razavi Khorasan Province for supplying the data used in this study.

\section{References}

Jensen. J. 2001. Genetic evaluation of dairy cattle using test-day models. Journal of Dairy Science. 84, $2803-2812$.

Mostert, B. E., Groeneveld E. and Kanfer, F.H.J. 2004. Test day models for production traits in dairy cattle. South African Journal of Animal Science 34 (supplement 2),35-37.

Swalve, H. H. 2000. Theoretical basis and computational methods for different test-day genetic evaluation methods. Journal of Dairy Science 83, 1115- 1124. 